\title{
Serpin $A 3 N$ is a novel hypothalamic gene upregulated by a high-fat diet and leptin in mice
}

\author{
Domenico Sergi', Fiona M. Campbell ${ }^{1}$, Christine Grant ${ }^{1}$, Amanda C. Morris ${ }^{1}$, Eva-Maria Bachmair ${ }^{1}$, \\ Christiane Koch ${ }^{2,3}$, Fiona H. McLean ${ }^{1}$, Aifric Muller ${ }^{1}$, Nigel Hoggard ${ }^{1}$, Baukje de Roos ${ }^{1}$, Begona Porteiro ${ }^{4,5}$, \\ Mark V. Boekschoten ${ }^{6}$, Fiona C. McGillicuddy ${ }^{7}$, Darcy Kahn ${ }^{1}$, Phyllis Nicol ${ }^{1}$, Jonas Benzler ${ }^{2,3}$, Claus-Dieter Mayer $^{8}$, \\ Janice E. Drew ${ }^{1}$, Helen M. Roche ${ }^{7}$, Michael Muller ${ }^{9}$, Ruben Nogueiras ${ }^{4,5}$, Carlos Dieguez ${ }^{4,5}$, Alexander Tups ${ }^{2,3}$ \\ and Lynda M. Williams ${ }^{1 *}$ (i)
}

\begin{abstract}
Background: Energy homeostasis is regulated by the hypothalamus but fails when animals are fed a high-fat diet (HFD), and leptin insensitivity and obesity develops. To elucidate the possible mechanisms underlying these effects, a microarray-based transcriptomics approach was used to identify novel genes regulated by HFD and leptin in the mouse hypothalamus.

Results: Mouse global array data identified serpinA3N as a novel gene highly upregulated by both a HFD and leptin challenge. In situ hybridisation showed serpinA3N expression upregulation by HFD and leptin in all major hypothalamic nuclei in agreement with transcriptomic gene expression data. Immunohistochemistry and studies in the hypothalamic clonal neuronal cell line, mHypoE-N42 (N42), confirmed that alpha 1-antichymotrypsin $\left(a_{1} A C\right)$, the protein encoded by serpinA3, is localised to neurons and revealed that it is secreted into the media. SerpinA3N expression in N42 neurons is upregulated by palmitic acid and by leptin, together with IL-6 and TNFa, and all three genes are downregulated by the anti-inflammatory monounsaturated fat, oleic acid. Additionally, palmitate upregulation of serpinA3 in N42 neurons is blocked by the NFKB inhibitor, BAY11, and the upregulation of serpinA3N expression in the hypothalamus by HFD is blunted in IL-1 receptor 1 knockout $\left(I L-1 R 1^{-/-}\right)$mice.
\end{abstract}

Conclusions: These data demonstrate that serpinA3 expression is implicated in nutritionally mediated hypothalamic inflammation.

Keywords: SerpinA3N, Hypothalamus, High-fat diet, Leptin

\section{Background}

Once considered problematic for only the Western, developed world, the burden of obesity today encompasses most countries [1], with shifts in global eating patterns causing detrimental changes in body weight and composition, associated diseases and decreased quality of life $[2,3]$. The development of effective treatments for obesity has not been fruitful, with the continued futility of dieting methodologies for sustained weight loss, and gastric surgery being the only current long-term solution [4-6], putting health care

\footnotetext{
* Correspondence: I.williams@abdn.ac.uk

${ }^{1}$ Rowett Institute, University of Aberdeen, Aberdeen AB25 2ZD, UK Full list of author information is available at the end of the article
}

systems under an enormous amount of pressure. In order for more effective, preventative measures to be put in place, it is crucial to understand the mechanisms that cause obesity. The overconsumption of energy-dense foods, particularly those high in long-chain saturated fat and sugar, appears to be a primary driving force behind the obesity epidemic [7]. These foods have been shown to have a powerful effect on the hypothalamus in rodent models, resulting in inflammation and astrogliosis that is implicated in diet-induced obesity [8-10].

Energy balance, food intake and consequently body weight are effectively regulated by a well-defined and complex hypothalamic system. Briefly, two distinct types of neurons have 
been identified as important in energy balance regulation: orexigenic neurons expressing neuropeptide Y (NPY) and agouti-related peptide (AgRP) and anorexigenic neurons expressing proopiomelanocortin (POMC) and cocaine- and amphetamine-regulated transcript (CART). Both orexigenic and anorexigenic neurons express leptin receptors, highlighting the importance of this hormones in the system. Leptin acts on multiple levels in hypothalamic neurons, effecting gene transcription, post-translational processing as well as membrane polarisation to inhibit AgRP/NPY neurons while activating POMC/CART neurons, resulting in a stable body weight [11]. In the obese state, the ability of leptin to regulate feeding behaviour as well as peripheral glucose homeostasis is diminished as a result of hypothalamic insensitivity to this hormone [12-16].

When animals are fed a high-fat diet (HFD), they ingest more energy than they expend, resulting in increased adiposity, and eventually obesity, suggesting that a HFD compromises the hypothalamic systems that regulate food intake. This has been confirmed in a number of rodent studies showing that a HFD induces inflammation in the hypothalamus activating microglia, astrocytes and neurons via a Toll-like receptor 4 (TLR4)-dependent mechanism [17-19] and the IKK $\beta / \mathrm{NFKB}_{\mathrm{K}} \mathrm{a}$ and JNK inflammatory pathways [20-24] resulting in leptin and insulin insensitivity. Blocking or inhibiting inflammation in the hypothalamus prevents leptin and insulin insensitivity and obesity induced by a HFD $[22,23,25,26]$.

In order to further explore the mechanisms linking HFD to hypothalamic dysfunction and leptin insensitivity, we carried out a microarray-based transcriptomics experiment to determine gene expression changes in response to a HFD as well as leptin challenge. One of the genes that was considerably upregulated by both leptin and HFD was serpinA3N, the gene encoding the anti-protease, alpha-1-antichymotrypsin $\left(\alpha_{1} A C\right)$. In the periphery, $\alpha_{1} \mathrm{AC}$ is an acute phase protein produced by hepatocytes [27] and has been recently identified as a marker of reactive astrogliosis in the brain [28]. Increased levels of $\alpha_{1} \mathrm{AC}$ in the brain are commonly associated with inflammatory conditions such as Alzheimer's disease $[29,30]$.

In the present study we identified, using transcriptomics, that the gene, serpinA3n, is highly expressed in the hypothalamus and is upregulated by leptin and HFD, a finding confirmed by semi-quantitative in situ hybridisation. Furthermore, we have shown that nutritional factors, as well as time on experiment, play a role in the hypothalamic nuclei-specific regulation of serpinA $3 N$ expression. As the expression of $\operatorname{serpin} A 3 \mathrm{~N}$ in the periphery has been reported to be dependent on inflammation and IL-1 stimulation [31-34], we tested the effect of HFD on hypothalamic serpinA3N expression in IL-1 receptor 1 knockout mice $\left(I L-1 R 1^{-/-}\right)$and in the hypothalamic clonal neuronal cell line, mHypoE-N42 (N42) which we challenged with oleic and palmitic acid, the latter, with and without blocking the NFKB pathway. In $I L-1 R 1^{-/-}$mice, HFD challenge failed to upregulate serpinA3N expression in contrast to wild-type mice and in N42 cells oleic acid downregulated serpinA3N while palmitate upregulated expression which was negated by inhibiting the $\mathrm{NFKB}$ pathway, confirming that HFD-induced expression is dependent on inflammation. Also, as increased serpinA3N expression in the brain has previously been identified as a marker of astrocyte activation [28], we examined $\alpha_{1} \mathrm{AC}$ immunoreactivity in the hypothalamus together with that of glial fibrillary acidic protein (GFAP), an astrocyte marker, ionised calcium binding adaptor molecule 1 (Iba1), a microglial marker, and NPY and AgRP, markers of neurons important in energy balance. Immunoreactive $\alpha_{1} \mathrm{AC}$ cells were larger and dissimilar to astrocytes and microglia having a distinctive neuronal shape and close associations with NPY and AgRP beaded fibres, also pointing to neuronal expression of serpinA3N. In addition, using Western blotting, the protein product of serpinA3N, $\alpha_{1} \mathrm{AC}$, was detected in $\mathrm{N} 42$ neurons in much lower levels than that found in the media demonstrating that the protein is secreted. The expression of serpin $A 3 N$ in and the secretion of $\alpha_{1} \mathrm{AC}$ from these cells confirmed neuronal expression of serpinA3N.

\section{Results}

\section{Transcriptomics}

Transcriptomic data revealed the regulation of serpi$n A 3 N$ gene expression in total dissected hypothalamic tissue from mice maintained on a LFD or HFD for 1 or 4 weeks and either challenged with vehicle or leptin. A three-way ANOVA showed significant effects of HFD $(P=0.0007)$, leptin challenge $\left(P=2.55 \times 10^{-6}\right)$, and time on diet $\left(P=1.34 \times 10^{-6}\right)$. However, there was no interaction between these factors (Fig. 1). A full list of changed genes can be found at NCBI's Gene Expression Omnibus and is accessible through GEO Series accession number GSE113943 (https://www.ncbi.nlm.nih.gov/ geo/query/acc.cgi).

\section{Localisation of serpinA3N and $a_{1} A C$ in the hypothalamus}

In situ hybridisation using a $\operatorname{serpin} A 3 N$-specific riboprobe revealed specific labelling throughout the hypothalamus with particularly high levels of expression in the arcuate nuclei (ARC), ventromedial $(\mathrm{VMH})$ and dorsomedial nuclei (DMH). The labelling extended out to the edges of the lateral hypothalamus (LH) (Fig. 2a). Immunoreactive $\alpha_{1} \mathrm{AC}$ in the ARC of the hypothalamus revealed a neuronal morphology (Fig. 2b-e). Dual staining using an anti-mouse $\alpha_{1} A C$ antibody (brown) alongside blue anti-GFAP (astrocyte specific) and anti-Iba1 (microglia specific) staining showed smaller and distinctly 


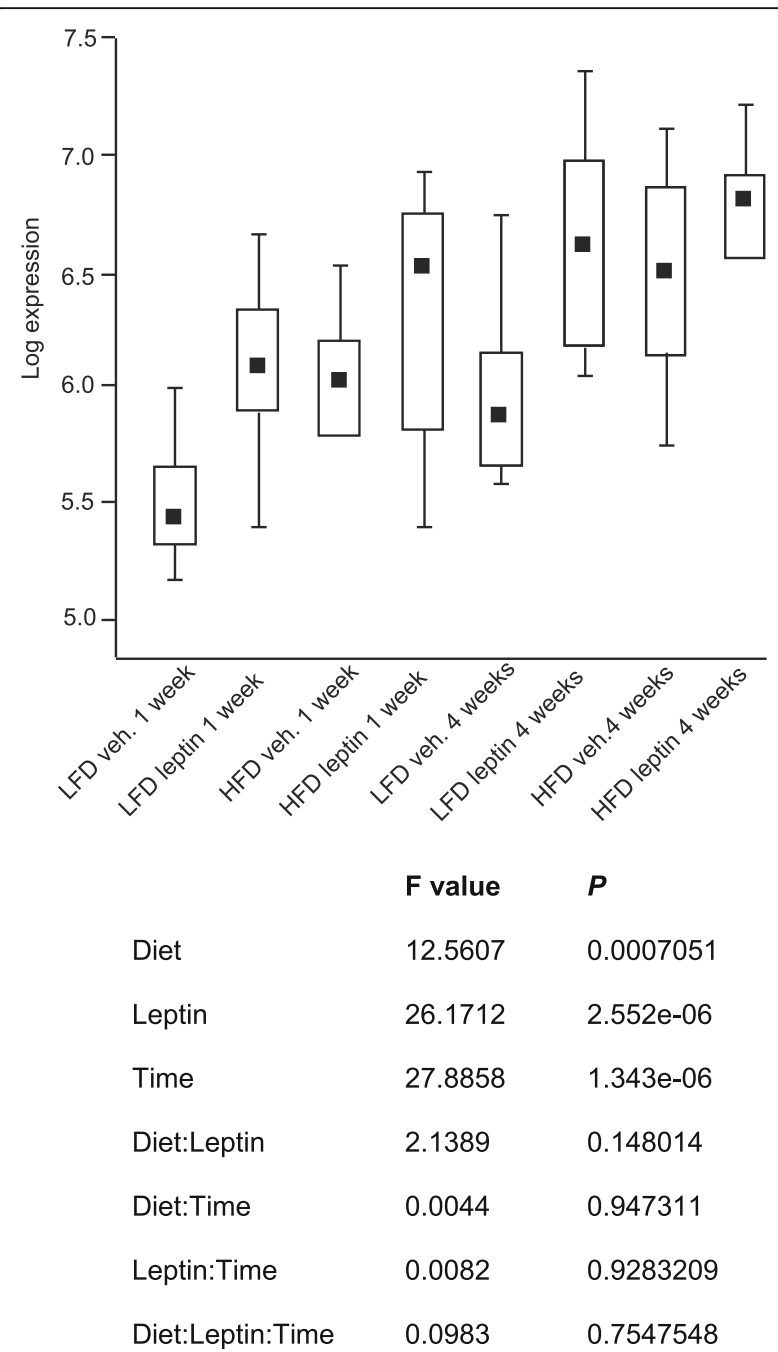

Fig. 1 Data derived from NuGO Affymetrics arrays from the hypothalamus of C57BL/6J mice maintained on a HFD or LFD for 1 and 4 weeks challenged with IP vehicle or leptin. The log of serpinA3N gene expression is represented by box and whisker plots. Three-way ANOVA showed a significant effect of diet, leptin challenge and time on the diet but no interaction between any of these factors $(n=10)$

different cell morphologies with closely associated but not overlapping staining (Fig. 2b, c). Staining with both anti-NPY and anti-AgRP (blue) showed beaded fibres closely associated with anti- $\alpha_{1} \mathrm{AC}$-positive neurons (brown) (Fig. 2d, e).

Regulation of serpinA $3 \mathrm{~N}$ and expression by HFD and time A robust increase in labelling was seen after just 1 week on a HFD. It was possible to distinguish distinct hypothalamic nuclei which expressed high levels of serpinA3N including the ARC, VMH, DMH, and LH (Fig. 3a, b). Quantification of hypothalamic nuclei including the ARC, $\mathrm{VMH}, \mathrm{DMH}$ (Fig. 3c-e) and LH (not shown) confirmed the increase in serpinA3N gene expression by a HFD seen in transcriptomics studies. Expression in the ARC was significantly increased by around $50 \%$ after 4 weeks on the HFD compared to LFD control (Fig. 3c). In comparison, the level of gene expression in the $\mathrm{VMH}$ and $\mathrm{DMH}$ was increased by approximately 2.5 and 4 times after only 1 week, respectively. After 16 weeks on the HFD, the labelling in these nuclei had increased to approximately eight times of that seen in LFD fed mice at week 1 (Fig. 3d, e). Analysis of the gene expression data by two-way ANOVA confirmed that serpin $A 3 N$ gene expression increased with time on the diet and there was no interaction between diet and time for the ARC and DMH but there was for the VMH $(P<0.05)$ indicating that the age of the animals may also lead to increases in serpinA3N gene expression in the ARC, VMH and DMH over the 16 weeks of the experiment (Fig. 3c-e).

\section{Regulation of serpinA3N expression by leptin}

To further investigate the regulation of $\operatorname{serpin} A 3 N$ by leptin, in situ hybridisation was carried out on both leptin-deficient mice $(o b / o b)$ and mice lacking functional leptin receptors $(d b / d b)$ and their lean littermates (Fig. 4a-d). Images from $o b / o b, d b / d b$ and lean mice show a much lower level of serpin $A 3 N$ gene expression in $o b / o b$ and $d b / d b$ mice (Fig. 4a, b). Quantification of labelling showed a difference of the order of seven to ten times lower levels of gene expression in $d b / d b$ and $o b / o b$ mice compared to their lean littermates (Fig. 4c, d).

Treatment of $o b / o b$ mice with leptin $(10 \mathrm{mg} / \mathrm{ml}$ injected IP) resulted in a time-dependent increase in serpinA3N expression with a 10-fold increase within $1 \mathrm{~h}$ and a 14-fold increase after $4 \mathrm{~h}$ (Fig. 4e). While leptin challenge in lean mice did not increase serpinA3N levels of expression above basal after $1 \mathrm{~h}$, leptin challenge did increase levels of expression significantly after $4 \mathrm{~h}$ but only by approximately $70 \%$ (Fig. 4f) compared to the 14-fold increase seen in $o b / o b$ mice $4 \mathrm{~h}$ after leptin challenge.

\section{Regulation of serpinA3N expression by HFD in the absence of leptin}

Transcriptomics data indicated that the effects of leptin and HFD were independent. To confirm this, $o b / o b$ mice, lacking leptin, were fed either a LFD (10\% of calories from fat), or a HFD ( $45 \%$ or $60 \%$ of calories from fat). The HFD led to a large increase in serpin $A 3 N$ gene expression compared to the LFD in the nuclei expressing the gene. Quantification of labelling showed an increase of around 20-30 times in both the ARC and the VMH after 8 weeks on a HFD (Fig. 5a, b).

\section{Regulation of serpin $A 3 N$ expression by fasting and refeeding}

In mice fasted for $24 \mathrm{~h}$, serpinA3N expression increased throughout the hypothalamus. Expression increased by around $40 \%$ in the ARC and $200 \%$ in the $\mathrm{VMH}$. 

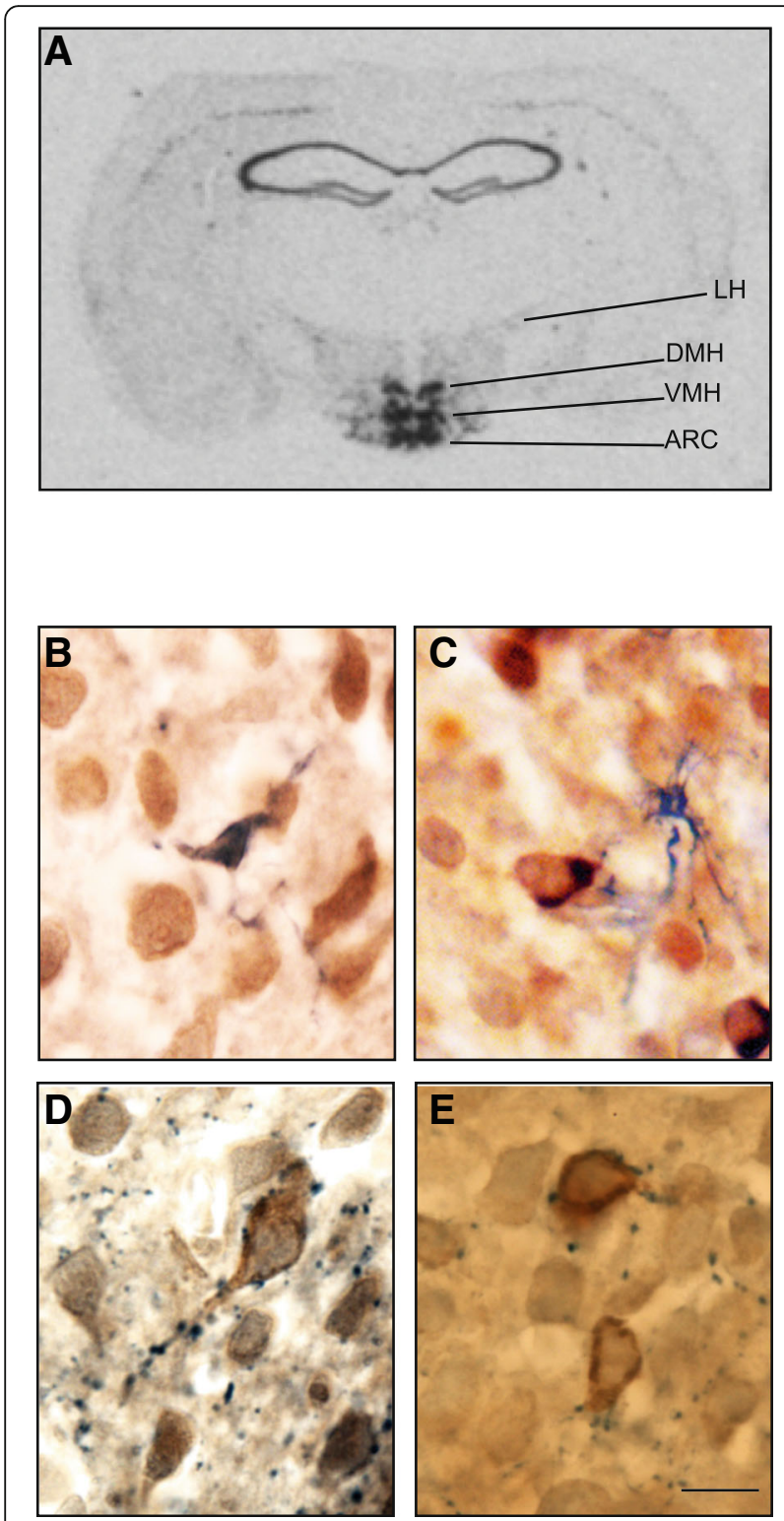

Fig. 2 a Representative in situ autoradiograph of a C57BL/6J mouse brain section after 4 weeks of HFD showing serpinA3N expression in the arcuate nuclei (ARC), the ventromedial nuclei of the

hypothalamus $(\mathrm{VMH})$, the dorsomedial nuclei of the hypothalamus $(\mathrm{DMH})$ and the lateral hypothalamus (LH). b-e Representative immunostaining of $a_{1} A C$ (brown) and $\mathbf{b}$ GFAP, $\mathbf{c ~ l b a 1 , ~ d ~ A g R P ~ a n d ~} \mathbf{e}$ NPY (all blue) in the arcuate nuclei after 1 week of HFD. Bar $=20 \mu \mathrm{m}$

Refeeding the mice for $24 \mathrm{~h}$ returned levels of expression to those seen in the fed animals (Fig. 6a, b).

\section{Regulation of serpinA3N by HFD in IL- $1 R 1^{-/-}$mice}

Feeding $I L-1 R 1^{-/-}$mice, a HFD for 8 weeks appeared to increase serpinA3N by a relatively small amount in the ARC, $\mathrm{VMH}$ and $\mathrm{DMH}$ compared to the effects seen in wild-type mice. There was substantial variability in the response to the HFD which failed to reach statistical significance (Fig. 7a-c).

\section{Regulation of SerpinA3N in N42 cultured hypothalamic neurons}

Leptin challenge upregulated serpin $A 3 N$ gene expression by twofold compared to vehicle-treated N42 neurons. IL-6 and $T N F \alpha$ were also upregulated. A similar effect was induced by $200 \mu \mathrm{M}$ palmitic acid. In comparison, $200 \mu \mathrm{M}$ oleic acid downregulated the gene expression of all three genes (Fig. 8a-c). The upregulation of serpinA3N, $I L-6$ and $T N F \alpha$ gene expression by palmitate was significantly reduced in the presence of the NFKB inhibitor, BAY11 (Fig. 8d-f).

\section{$a_{1} A C$ secretion from $N 42$ cultured neurons}

SDS-PAGE gels of media from cultured N42 neurons showed the presence of several protein bands of different molecular weights but not in cell free media (Fig. 9). Using Western blotting, cell free media displayed extremely faint immunoreactive $\alpha 1 \mathrm{AC}$ bands but culture media from N42 neurons showed two immunoreactive bands, the lower at $59 \mathrm{kDa}$ corresponding to the molecular weight of $\alpha_{1} \mathrm{AC}$ (positive control). The band above may correspond to a different post-translationally modified form of the protein. The cell lysate in contrast showed only extremely faint immunoreactive bands including one at $59 \mathrm{kDa}$ (Fig. 9).

\section{Discussion}

Hypothalamic inflammation in response to a HFD in rodents is well-documented after both short- and long-term exposure to HFD $[17-19,35,36]$. In the present study transcriptomics data show that, a so far unreported gene, associated with inflammation in the periphery, serpin $A 3 N$, is strongly upregulated by HFD and leptin in the hypothalamus. An incidental finding is that $\operatorname{serpin} A 3 N$ is also upregulated by time on experiment which corresponds to the increasing age of the mice. Surprisingly, these effects were largely independent of one another indicating that while hypothalamic serpi$n A 3 N$ expression is regulated by a number of factors these appear to act via independent pathways.

It can be difficult to differentiate between the effects of a HFD and that of diet-induced obesity as the former rapidly leads to the latter. In the present study, the effects of obesity and a HFD are separated in obese $o b / o b$ mice, which, though obese, normally have relatively low levels of hypothalamic serpinA $3 N$ gene expression, but when challenged with a HFD, the level of expression is rapidly upregulated demonstrating that the level of serpi$n A 3 N$ expression is regulated by a HFD rather than obesity per se. Also, the possibility that increased caloric intake rather than diet composition is responsible for the upregulation of serpinA3N cannot be ruled out completely in our animal studies. However, $o b / o b$ mice are hyperphagic, but as noted above, they express relatively 
A

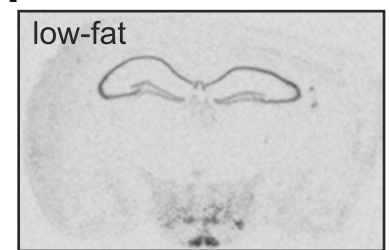

B

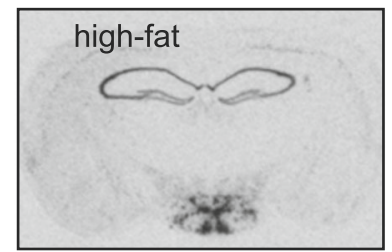

\section{C}
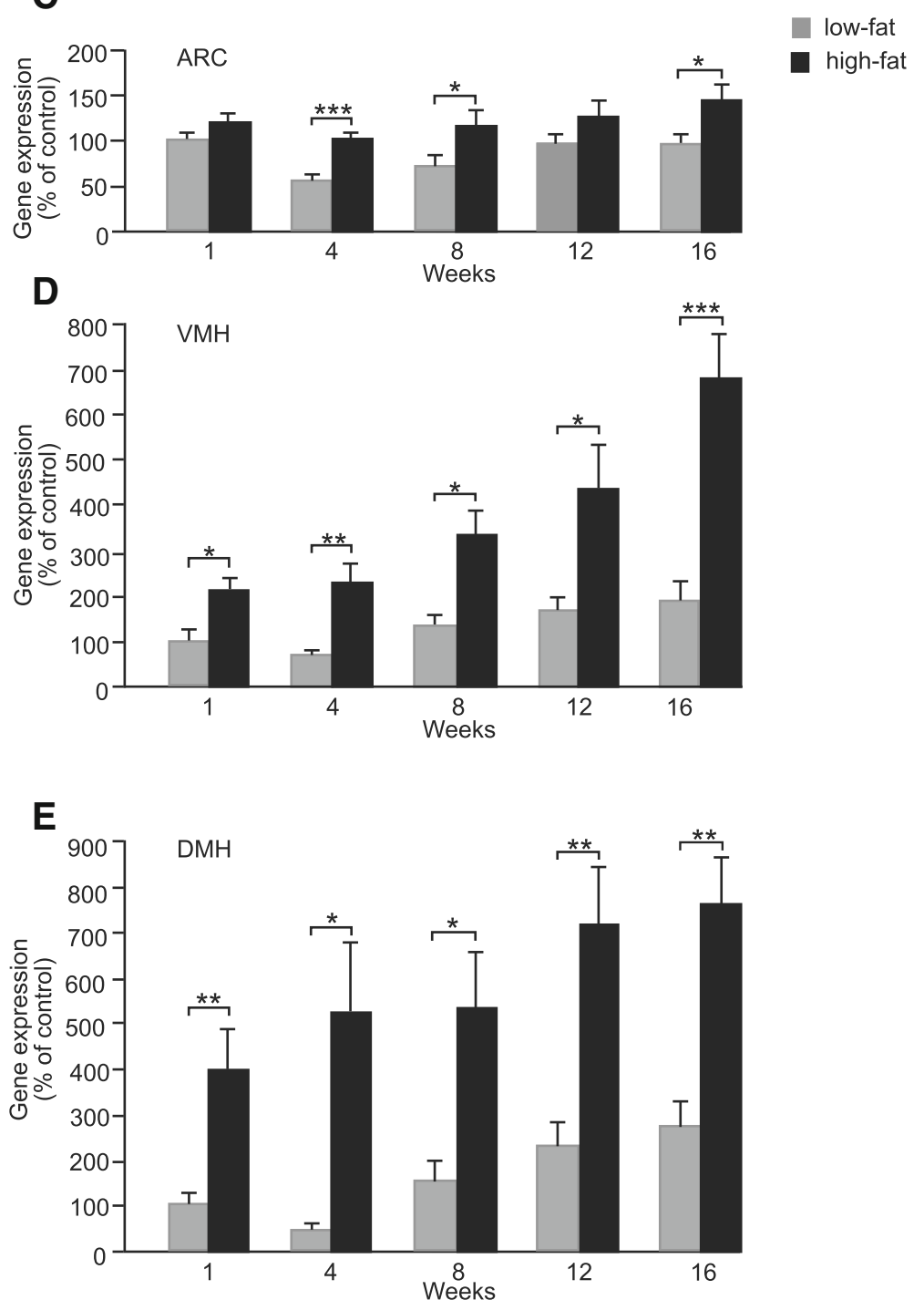

Fig. 3 Representative in situ autoradiographs of C57BL/6J mouse brain sections showing serpinA3N expression in a LFD-fed mouse and $\mathbf{b}$ HFDfed mouse. Levels of serpinA3N gene expression in LFD- and HFD-fed mice measured by semi-quantitative in situ hybridisation $\mathbf{c}$ in the arcuate nuclei (ARC), $\mathbf{d}$ the ventromedial nuclei of the hypothalamus (VMH) and $\mathbf{e}$ the dorsomedial nuclei of the hypothalamus (DMH). Two-way ANOVA showed a significant effect of diet $P<0.001$ for the ARC, VMH and DMH and time $P<0.001$ for the $\mathrm{VMH}$ and $P<0.05$ for the ARC and DMH with an interaction between diet and time $P<0.05$ for the VMH only. One-way ANOVA showed differences between HFD and LFD from 4 weeks onwards for the ARC and for all times tested for the VMH and DMH. ${ }^{*} P<0.05,{ }^{* *} P<0.01,{ }^{* * *} P<0.001(n=6)$ 
A

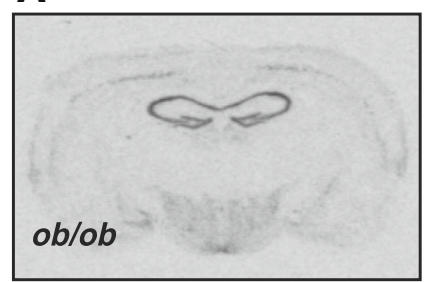

C

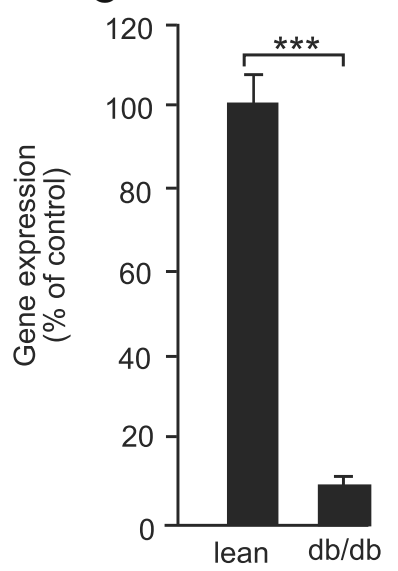

E

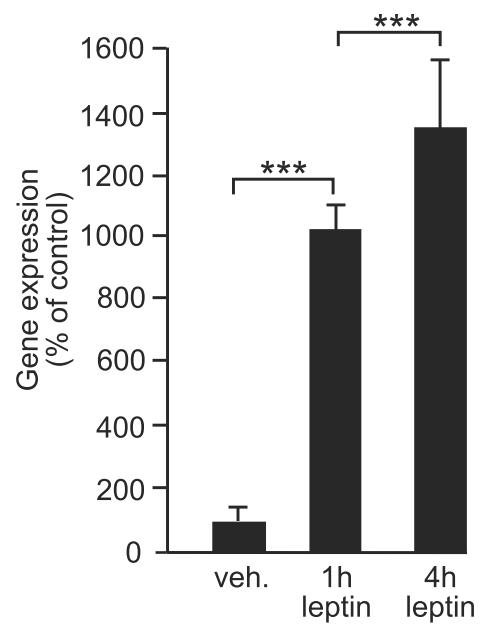

B

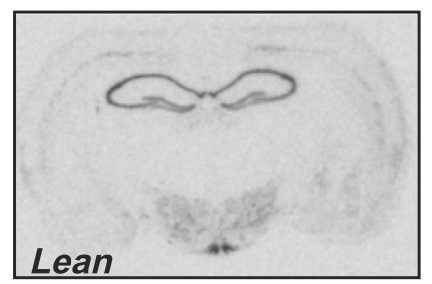

D

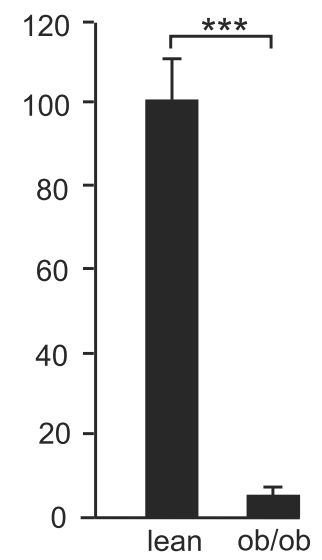

F

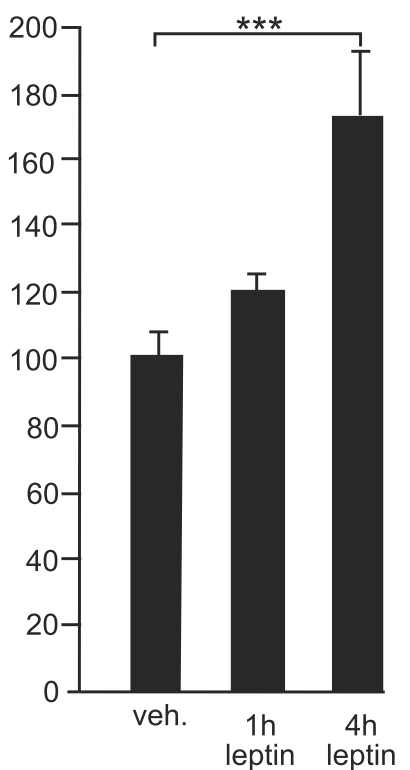

Fig. 4 Representative in situ autoradiographs of mouse brain sections showing serpinA3N expression in a ob/ob mouse on a C57BL/6J background and $\mathbf{b}$ lean C57BL/6J mouse. Levels of serpinA3N gene expression in the arcuate nuclei measured by semi-quantitative in situ hybridisation of $\mathbf{c} d b / d b$ on a C57BL/6J background and lean C57BL/6J mice, $\mathbf{d}$ ob/ob and lean mice, e ob/ob mice injected with IP vehicle (veh.) or leptin after either 1 or $4 \mathrm{~h}$ (h) and $\mathbf{f}$ lean mice injected with IP vehicle (veh.) or leptin after either 1 or $4 \mathrm{~h}(\mathrm{~h})$. ${ }^{* *} P<0.001(n=6)$

low levels of hypothalamic serpin $A 3 N$ when not exposed to a HFD. Additionally, the pro-inflammatory long-chain saturated fat, palmitic acid, upregulates expression of serpin $A 3 N$ in the clonal neuronal cell line N42, while oleic acid, an anti-inflammatory monounsaturated fatty acid, decreases gene expression indicating that fatty acids have a direct effect on serpinA3N expression in neurons, supporting the contention that $\operatorname{serpin} A 3 \mathrm{~N}$ expression responds to the increased long-chain saturated fat in the diet rather than to increased caloric intake. 
A

Ob/ob ARC

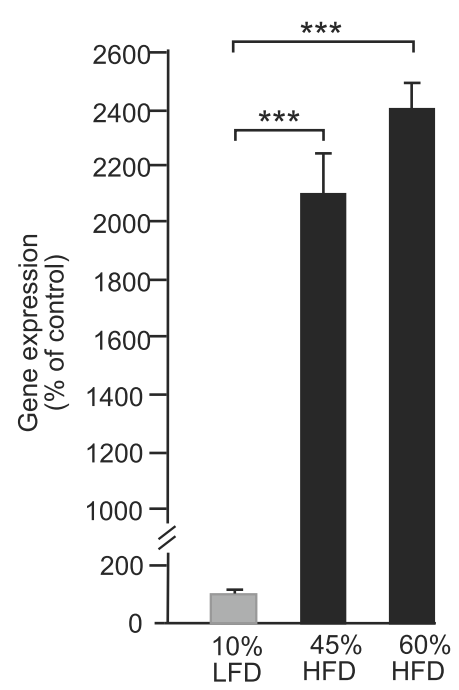

B $\mathrm{Ob} / \mathrm{ob} \mathrm{VMH}$

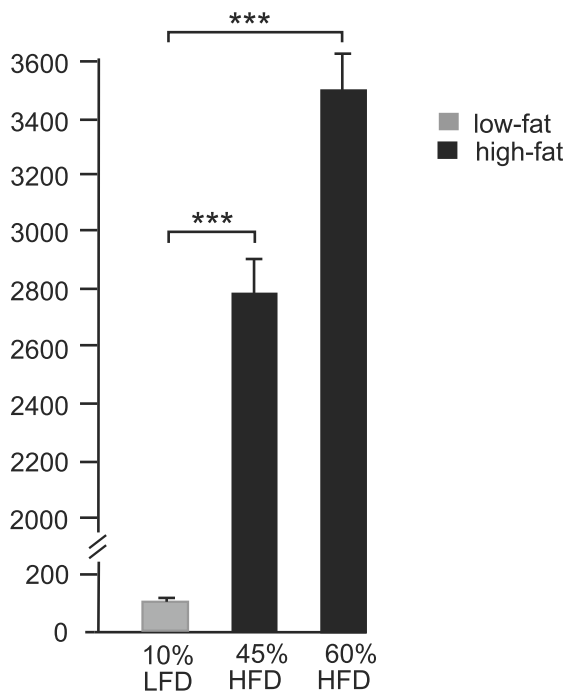

Fig. 5 Levels of serpinA3N gene expression measured by semi-quantitative in situ hybridisation in the $\mathbf{a}$ arcuate nuclei (ARC) and $\mathbf{b}$ ventromedial nuclei of the hypothalamus (VMH) of ob/ob mice fed either a LFD, 10\% energy ( $\mathrm{kCal}$ ) from fat, or HFD either $45 \%$ or $60 \%$ energy ( $\mathrm{kCal}$ ) from fat for 8 weeks. ${ }^{* * *} P<0.001(n=6)$

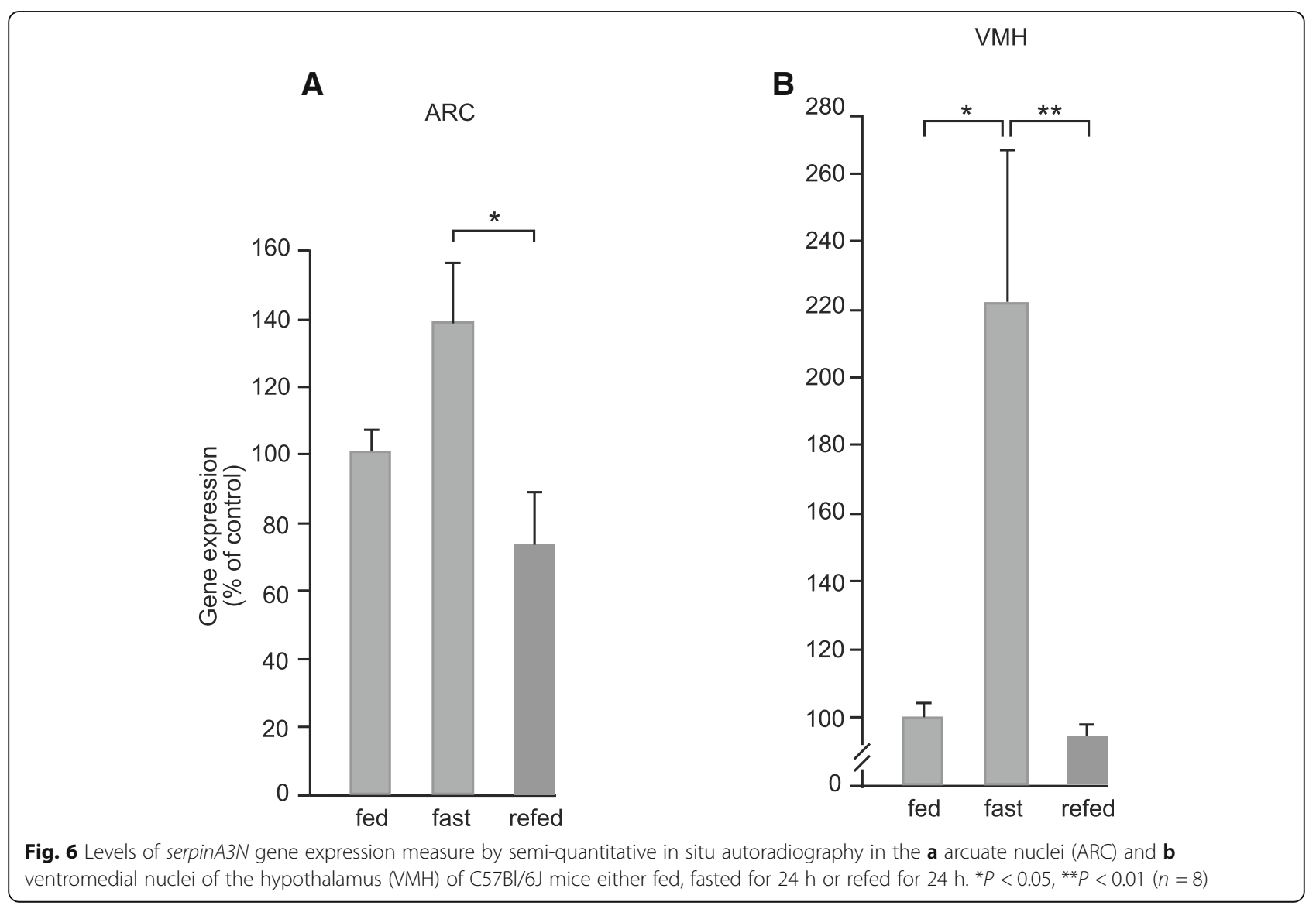


A

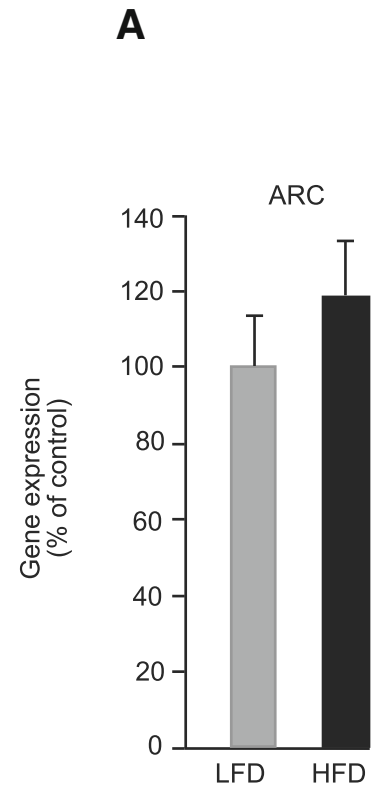

B

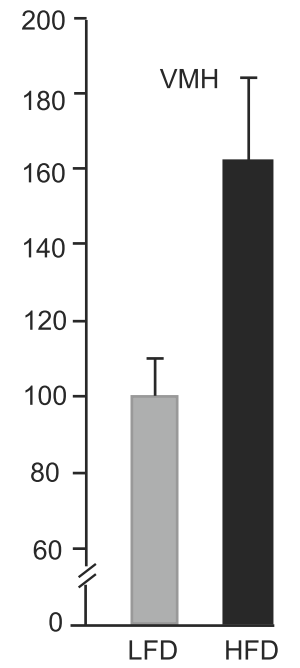

C

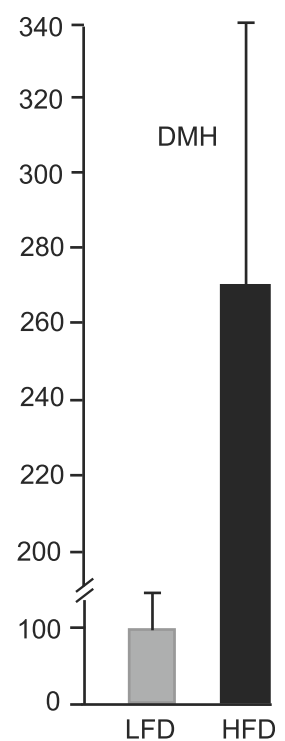

Fig. 7 Levels of serpinA3N gene expression measured by semi-quantitative in situ autoradiography in the a arcuate nuclei (ARC), $\mathbf{b}$ ventromedial nuclei of the hypothalamus $(\mathrm{VMH})$ and $\mathbf{c}$ dorsomedial nuclei of the hypothalamus $(\mathrm{DMH})$ in $/ \mathrm{L}-1 \mathrm{R} 1^{-1-}$ mice on a $\mathrm{C} 57 \mathrm{BL} / 6 \mathrm{~J}$ background fed either a LFD or HFD for 8 weeks ( $n=9$ for HFD and $n=5$ for LFD)

In the periphery, $\alpha_{1} \mathrm{AC}$, the protein encoded by serpi$n A 3 N$, serves as an acute phase protein produced by the liver, in response to inflammation and binds to proteases, thus limiting inflammation-related damage [37, 38]. In the brain, $\alpha_{1} \mathrm{AC}$ has been shown to be associated with inflammation and elevated levels are found in Alzheimer's disease, closely linked with amyloid plaques [38-40]. Other observed functions of peripheral $\alpha_{1} \mathrm{AC}$ include inhibition of oxygen uptake and superoxide generation in granulocytes [41], DNA binding independent of its anti-protease activity, regulation of its own gene expression, and inhibition of DNA polymerase and DNA primase activity [42, 43]. However, the target protein for, and the function of, $\alpha_{1} \mathrm{AC}$ in the hypothalamus remains to be identified.

In the present study, in situ hybridisation revealed a widespread localisation of serpinA $3 N$ expression throughout the hypothalamus in a pattern corresponding to major nuclei indicating that the expression is neuronal. This is further supported by immunohistochemistry where dual immunostaining for $\alpha_{1} \mathrm{AC}$ and both the astrocyte marker, GFAP, and the microglial marker Iba1 reveal no overlap in staining and immunopositive $\alpha_{1} \mathrm{AC}$ show a characteristic neuronal shape which is both larger and distinctly different from that of GFAP and Iba1 immunopositive cells. Dual staining with NPY and AgRP shows close associations between $\alpha_{1} \mathrm{AC}$ immunopositive fibres and NPY and AgRP beaded fibres. Also, in N42 clonal neurons in culture, which have been used previously to investigate hypothalamic control mechanisms [44], the expression of serpinA $3 N$ is upregulated by both leptin and palmitate in a manner consistent with that seen in the hypothalamus in response to leptin challenge and a HFD. Taking all of this evidence together, serpin $A 3 N$ measured in the present study appears largely neuronal in origin. Nonetheless, in a previous genomic study involving two mouse models of brain injury (ischemic stroke and neuroinflammation), serpinA3N was identified as a marker of reactive astrogliosis [28], and as HFD has been shown to induce astrogliosis in mice $[17,45]$, then potentially, some of the increase in serpinA3N expression may be astrocytic. Thus, we cannot rule out that part of the increased gene expression seen may occur in astrocytes.

In the liver, increased levels of serpin $A 3 N$ gene expression and subsequently increased levels of $\alpha_{1} \mathrm{AC}$, like all acute phase proteins, are stimulated by inflammation, particularly by raised circulating levels of IL- 6 and IL- 1 type cytokines working via STAT3 activation and increased NFkB [46]. In N42 neurons, both $I L-6$ and $T N F \alpha$ were upregulated in parallel with serpin $A 3 N$ by leptin and palmitic acid, with palmitic acid stimulated gene expression inhibited by BAY11 blocking the NFKB pathway. These results together with the lack of HFD-induced serpinA3N upregulation in $I L-1 R 1^{-/-}$mice clearly indicated that hypothalamic serpin $A 3 N$ is involved in the inflammatory response as in the periphery.

Leptin stimulates the release of IL-1 $\beta$ in the hypothalamus [47] while a HFD does not appear to upregulate $I L-1 \beta$ in this brain area [17] but IL-1 $\beta$ does increase in the periphery in obesity [48] indicating a more complex relationship between HFD, IL-1 $\beta$ and $\operatorname{serpin} A 3 N$ 
A

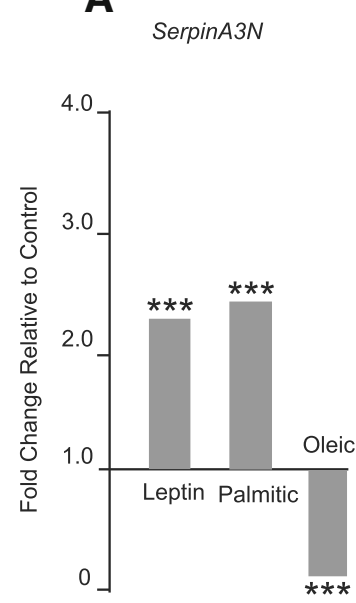

D

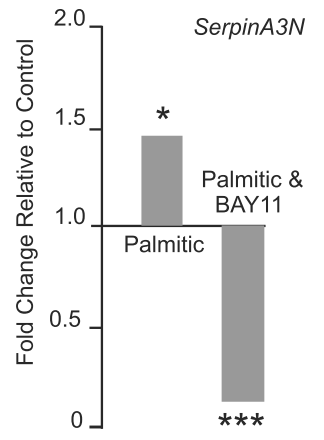

B

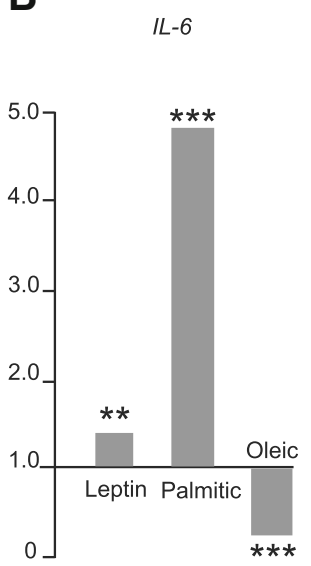

E

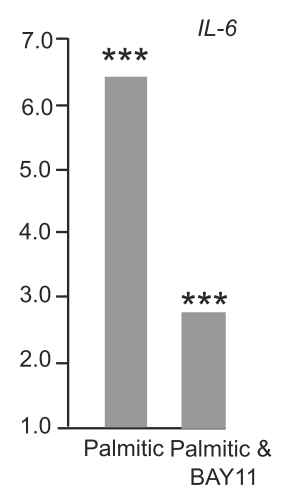

C

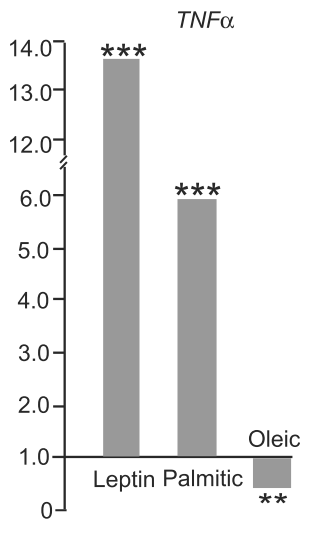

$\mathbf{F}$

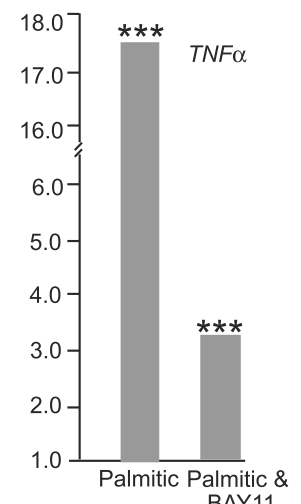

Fig. 8 a-f In mHypoE-N42 cells, a-c SerpinA3N, IL-6 and TNFa gene expression were all upregulated by leptin and palmitic acid challenge and downregulated by oleic acid. $\mathbf{d}-\mathbf{f}$ The upregulation of SerpinA3N, IL-6 and TNFa gene expression by palmitic acid was blocked by the NKKB inhibitor BAY11. $P<0.05,{ }^{* * *} P<0.001,{ }^{* *} P<0.01$. NS not significant

upregulation. Circulating interleukins do not readily cross the blood-brain barrier but influence the brain via intermediate mechanisms [49]. The source of the interleukins and the mechanisms underlying upregulation of serpi$n A 3 N$ expression by a HFD requires further investigation. While there is no significantly different upregulation of serpinA3N gene expression in $I L-1 R 1^{-/-}$mice, there is an indication of a variable response to HFD which may be due to increases in circulating leptin levels in response to increasing adiposity and, thus, increasing leptin levels.

While in the absence of leptin, signalling levels of serpi$n A 3 N$ expression in the hypothalamus are low and leptin challenge upregulates serpinA3N expression, the localisation and pattern of leptin-stimulated expression differs from that induced by a HFD. Leptin-induced $\operatorname{serpin} A 3 N$ expression increases mainly in the $\mathrm{ARC}, \mathrm{VMH}$ and throughout the hypothalamus up to the borders of the $\mathrm{LH}$ with no clear demarcation of hypothalamic nuclei other than the ARC and VMH. The role of leptin in the stimulation of serpin $A 3 N$ expression on a HFD, however, appears to be relatively small as a HFD upregulates $\operatorname{serpin} A 3 N$ gene expression to a much greater degree in $o b / o b$ mice, in the absence of leptin, compared to lean mice in the presence of leptin. The reasons for this are not clear, but counterintuitively, it may be that the presence of leptin is somehow protective against the induction of $\operatorname{serpin} A 3 N$ gene expression by a HFD. Leptin receptors are present on both neurons and astrocytes and leptin may be upregulating $\operatorname{serpin} A 3 N$ in either or both these cell types [50], with the upregulation of serpinA3N in N42 hypothalamic neurons confirming the neuronal regulation of $\operatorname{serpin} A 3 N$ by leptin. Nonetheless, circulating leptin levels do not appear to be a major regulator of $\operatorname{serpin} A 3 N$ gene expression in the fasting and refed states as the regulation or serpi$n A 3 N$ occurs in opposition to circulating leptin levels, with fasting, which causes leptin levels to drop, increasing 


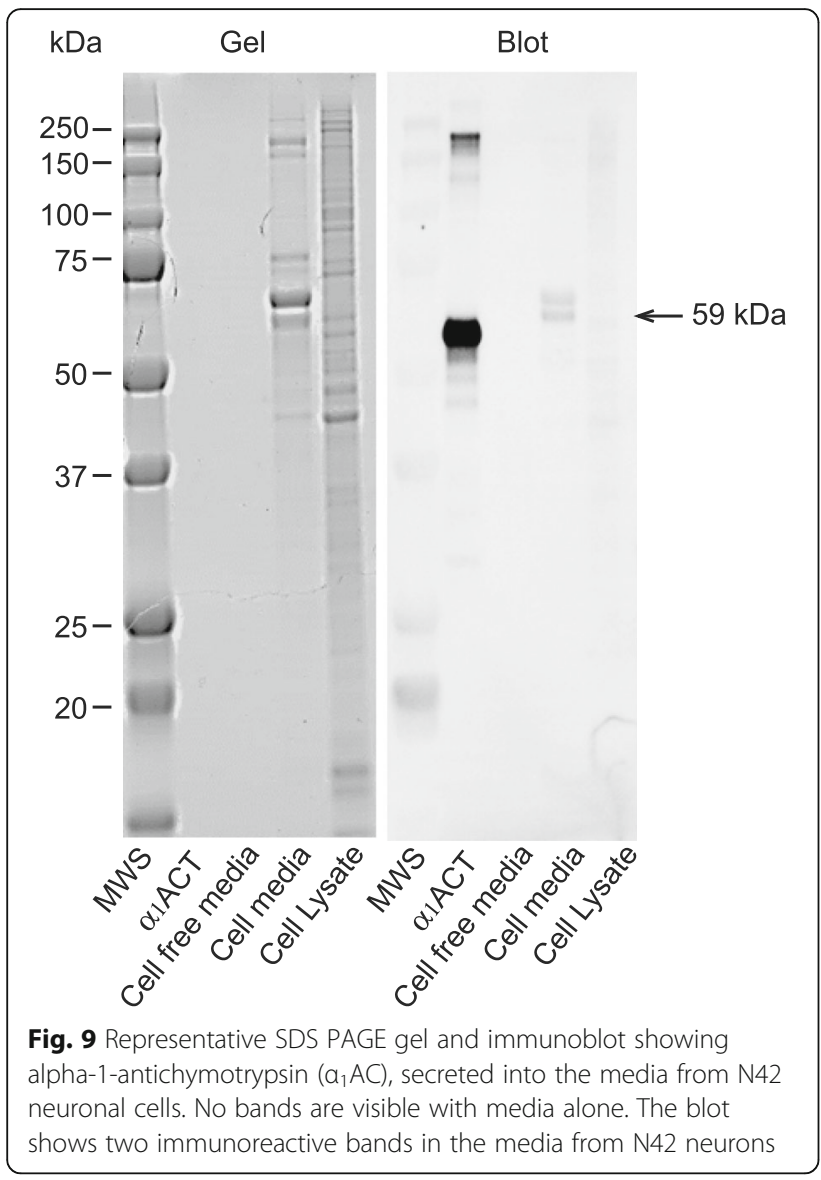

serpin $A 3 N$ gene expression, while refeeding, which increases circulating leptin levels [51], results in decreased serpin $A 3 N$ gene expression. However, this may be explained by the stimulation of $\operatorname{serpin} A 3 N$ gene expression by the increased levels of circulating free fatty acids which occur during fasting [52].

Leptin insensitivity, induced by a HFD, is well documented [22]. While this concept was not specifically tested in the present study, the transcriptomics data which combined leptin challenge on a LFD and HFD indicated that the effect of diet was separate from that of leptin challenge and that there was no interaction between the two indicating that upregulation of $\operatorname{serpin} A 3 N$ gene expression by leptin is unaffected by HFD; however, this remains to be specifically tested.

Increased time on experiment or age of the mice also appears to be a factor in the upregulation of $\operatorname{serpin} A 3 N$ gene expression in the ARC, VMH and DMH of the hypothalamus. Although the effects of extreme ageing were not investigated in the present study, the mice were older at the end of both the transcriptomics and the in situ hybridisation studies on HFD than at the beginning and both showed a clear effect on serpinA3N gene expression with time despite being measured by different approaches. The mice exposed to the HFD for the longest period of time varied in age between 12 weeks at the beginning of the study and 28 weeks at the end on the study. Twelve weeks of age corresponds to a young mature adult, and 28 weeks corresponds to early middle age with mice showing some signs of age-related changes [53]. Ageing has also been reported to induce inflammation in the hypothalamus via the IKK $\beta / N_{F} B$ pathway. Indeed, hypothalamic inflammatory changes have shown to control systemic ageing demonstrating the importance of this phenomenon to the health of the whole organism [54].

\section{Conclusions}

We have shown the upregulation of a novel hypothalamic gene, $\operatorname{serpin} A 3 N$, by HFD and leptin. Increasing age and fasting also resulted in an upregulation although to a lesser extent. The upregulation of $\operatorname{serpin} A 3 N$ expression by leptin and palmitic acid was confirmed in N42 neurones in culture along with the upregulation of $I L-6$ and $T N F \alpha$, two classical markers of inflammation. Blocking the NFkB inflammatory pathway by BAY11 not only prevented the upregulation of $I L-6$ and TNF $\alpha$, but also that of serpinA3N. The protein product of serpi$n A 3 N, \alpha_{1} \mathrm{AC}$, is found in the media from cultured N42 neurons but is difficult to visualise within the cell lysate indicating that $\alpha_{1} \mathrm{AC}$ is a secreted protein in the hypothalamus as it is in the periphery.

These data strongly support the contention that serpi$n A 3 N$ expression is a marker of inflammation in the hypothalamus regulated by nutritional status and leptin and indicate a potential role for $\alpha_{1} \mathrm{AC}$ in hypothalamic inflammation and the regulation of energy balance.

\section{Methods}

\section{Animal studies}

All experiments were carried out according to the institutional and national guidelines of the European Convention of Vertebrate Animals Used for Experimentation, under European Council Directive 86/609/EEC dated November 1986. For the transcriptomics studies, male, 16-week-old, C57BL/6J mice were obtained from Charles River laboratories (Maastricht, The Netherlands) and housed in pairs in the light- and temperature-controlled animal facility of Wageningen University (12:12-h light/dark cycle at $\left.22^{\circ} \mathrm{C}\right)$. Mice were maintained for 1 or 4 weeks on either a HFD (45\% kCal from fat) or LFD (10\% kCal from fat) (Research Diet Services BV, Wijk bij Duurstede, The Netherlands) modelled on (D12451 and D12450B respectively Research Diets, NJ, USA). (Please see https://researchdiets.com/ opensource-diets/dio-series-diets for diet composition details). For this study, palm oil was used in place of lard. They were then challenged with three intraperitoneal (IP) injections of murine leptin ( $2 \mathrm{mg} / \mathrm{kg}$ body weight) ( $\mathrm{R} \& \mathrm{D}$ Systems, Abingdon, UK) or carrier at 24, 15 and approximately $3 \mathrm{~h}$ prior to killing in the early morning $(n=10)$. 
This experiment was part of the NuGO Proof of Principle studies as previously described [55].

To further investigate the regulation of serpinA3N gene expression on a HFD, male C57BL/6J mice (Harlan, Bicester, UK), aged 12 weeks, were singly housed on grid floors and fed either a HFD $(60 \% \mathrm{kCal}$ from fat) or a LFD $(10 \%$ kCal from fat) (D12452 and D12450B respectively, Research Diets, NJ, USA-see web site above for detailed dietary breakdown), ad libitum for 3 days, $1,4,8,12$ or 16 weeks and killed either by exsanguination or by perfusion fixation (1 week) with $4 \%$ paraformaldehyde in phosphate buffered saline (PBS) under terminal anaesthesia $(n=6)$. To further investigate the upregulation of serpi$n A 3 N$ by leptin, male mice on the C57BL/6J background either leptin deficient $(o b / o b)$ or lacking functional leptin receptors $(d b / d b)$ and their lean littermates (Harlan, Bicester, UK) were killed for in situ hybridisation $(n=6)$. Leptin-deficient $o b / o b$ mice and lean littermates $(n=6)$ were also challenged with vehicle or leptin by intraperitoneal (IP) injection ( $2 \mathrm{mg} / \mathrm{kg}$ body weight) and killed either 1 or $4 \mathrm{~h}$ later as detailed above. Food intake in response to leptin was not measured at this time because any changes were deemed to be impractical to measure with any accuracy due to the fact that leptin challenge was carried out over such a short period of time during the light period when food intake is already low. To confirm the upregulation of serpinA3N expression by HFD is independent from that of leptin, $o b / o b$ mice were fed either a LFD 10\% kCal from fat or a HFD either $45 \%$ or $60 \% \mathrm{kCal}$ from fat in the form of lard (diets detailed above) for 8 weeks prior to killing by exsanguination.

To test the effect of nutritional status on hypothalamic serpin $A 3 N$ gene expression, C57BL/6J mice were fasted for $24 \mathrm{~h}$ or fed ad libitum on standard mouse diet prior to killing. Refed animals were allowed access to food ad libitum for a period of $24 \mathrm{~h}$ after fasting $(n=8)$.

To test the possibility that inflammation plays a role in the effect of HFD on the expression of serpinA3N, mice from $I L-1 R 1^{-/-}$breeding pairs, on C57BL/6J background, purchased from Jackson laboratories were bred at University College Dublin (UCD) for 6-10 generations under specific pathogen-free conditions. Male IL- $1 \mathrm{R} 1^{-/-}$mice were then fed HFD, $45 \% \mathrm{kCal}$ or LFD, $10 \% \mathrm{kCal}$ from fat for 12 weeks prior to killing (D12451 and D12450B respectively, Research Diets, NJ, USA). In this study, palm oil was used instead of lard ( $n=9$ HFD and $n=5$ chow).

\section{Transcriptomics}

Hypothalami were dissected and snap-frozen in liquid nitrogen and stored at $-80{ }^{\circ} \mathrm{C}$ until RNA extraction. Total RNA was extracted using TRIzol reagent (Invitrogen, Carlsbad, CA), and the mRNA purified with RNeasy Mini Kit (Qiagen, Venlo, The Netherlands) with $1 \% \beta$-mercapto ethanol and treated with DNAse. The mRNA integrity was checked on an Agilent 2100 Bioanalyzer (Agilent Technologies, Amsterdam, The Netherlands) (average RIN 9.2), and individual RNA samples (4 $\mu$ g per animal) were labelled and hybridised on a Affymetrix NuGO mouse array as described previously [35].

\section{In situ hybridisation}

The riboprobe for serpinA3N, accession no. BC013651, was derived using the forward primer 5'CTACGCGGG CAAGAGGA3' and the reverse primer 5'AAGG GGGCAATTTCAGTTT3'. The size of the amplified insert was $543 \mathrm{bp}$. Automated sequencing was performed to verify the probe sequence.

Messenger RNA levels were quantified by in situ hybridisation, on $20-\mu \mathrm{m}$ thick coronal hypothalamic cryo-sections, using techniques described in detail elsewhere [56]. Briefly, slides were fixed in $4 \%(w / v)$ paraformaldehyde in $0.1 \mathrm{~mol} / \mathrm{l}$ PBS for $20 \mathrm{~min}$ at room temperature, washed in PBS, incubated in $0.1 \mathrm{mmol} / 1$ triethanolamine for $2 \mathrm{~min}$ and acetylated in $0.1 \mathrm{mmol} / \mathrm{l}$ triethanolamine and $0.25 \%(\mathrm{v} / \mathrm{v})$ acetic anhydride for $10 \mathrm{~min}$. Sections were dehydrated in ethanol and dried under vacuum before hybridisation with riboprobes at $10^{6} \mathrm{cpm} / \mathrm{ml}$ for $18 \mathrm{~h}$ at $58{ }^{\circ} \mathrm{C}$. After hybridisation, sections were desalted through a series of washes in standard saline citrate (SSC) to a final stringency of $0.1 \times \mathrm{SSC}$ at $60{ }^{\circ} \mathrm{C}$ for $30 \mathrm{~min}$, treated with RNase A and dehydrated in ethanol. Slides were apposed to Biomax MR (Sigma-Aldrich, UK) together with $\left[{ }^{14} \mathrm{C}\right]$ micro-scale standards (Amersham International, Amersham, UK) at room temperature for varying lengths of time depending on the probes used to ensure that the optical density of areas to be measured fall within the linear region of the standard curve.

Autoradiographs were scanned on a Umax Power Look II (UMAX Data Systems, Fremont, CA, USA). Integrated optical densities (IOD) of specific nuclei were quantified with reference to a mouse brain atlas [57] using the Image Pro-plus system (Media Cybernetics, Silver Springs, MD, USA). IOD was converted to $\mathrm{nCi} / \mathrm{g}$ using $\left[{ }^{14} \mathrm{C}\right]$ microscale standard curves for measures of total gene expression.

\section{Immunohistochemistry}

Frozen sections $(20 \mu \mathrm{m})$ were first incubated with goat anti-mouse serpinA3N (R\&D Systems cat. no. AF4709) at a dilution of 1:1000 overnight at $4{ }^{\circ} \mathrm{C}$ then incubated for $30 \mathrm{~min}$ at room temperature with biotinylated anti-goat IgG (Vector Labs cat. no. PK-6105) according to the manufacturer's instructions followed by $\mathrm{ABC}$ reagent (Vector Labs cat. no. PK-6105) and stained with 3,3'-diaminobenzidine (DAB) substrate solution (brown) (Vector Labs cat. no. SK-4100). Sections were then thoroughly washed and incubated with either chicken anti-GFAP (Millipore, UK cat. no. AB5541), rabbit anti-IbA1 (Wako cat. no. 019-19741), rabbit anti-NPY (ThermoFisher Scientific cat. no. PA5-19568) or rabbit anti-AgRP (Phoenix 
Pharmaceuticals cat. no. H-003-57) at a dilution of 1:300 overnight at $4{ }^{\circ} \mathrm{C}$ and then at room temperature for 30 min with either goat anti-chicken IgG (Vector Labs cat. no. BA-9010) at a dilution of 1:200 followed by Vectastain Elite $\mathrm{ABC}$ kit (goat IgG) (Vector Labs cat. no. PK-6105) or directly with the Vectastain Elite ABC kit (goat IgG) and stained with Vector SG (blue) (Vector Labs cat. no. SK-4700). Control sections omitted the primary antibodies.

\section{Neuronal culture and reagents}

To investigate the regulation of $\operatorname{serpin} A 3 N$ gene expression specifically in neurons, the embryonic immortalised hypothalamic cell line, N42, was used (Cellution Biosystems Inc., Ontario, Canada. Please see https://www.cedarlanelabs.com/ Products/Detail/CLU122 for a comprehensive list of all genes expressed by these cells including the leptin receptor). These cells have been previously shown to provide a good model for hypothalamic neuron gene expression studies [44].

Cells were cultured in Dulbecco's modified Eagle's medium (DMEM) (Life Technologies, Paisley, UK) supplemented with $10 \%$ fetal bovine serum and $1 \%$ penicillin/streptomycin (Life Technologies) maintained at $37^{\circ} \mathrm{C}$ under $5 \% \mathrm{CO}_{2}$. Neurons were grown in $60-\mathrm{mm}$ plates $(n=6)$ to $90 \%$ confluence then challenged with either $50 \mathrm{nM}$ leptin (R\&D Systems, Abingdon, UK), $200 \mu \mathrm{M}$ palmitic acid or $200 \mu \mathrm{M}$ oleic acid conjugated to fatty acid-free bovine serum albumin (BSA) (Sigma-Aldrich, UK), or the appropriate vehicle as a control. For leptin, this was a mixture of $12 \mu \mathrm{M} \mathrm{HCl}$ and $6 \mu \mathrm{M} \mathrm{NaOH}$ and for fatty acids $50 \mu \mathrm{M}$ fatty acid-free BSA. To inhibit the NFkB pathway, N42 neurons were treated with $50 \mu \mathrm{M}$ BSA or $200 \mu \mathrm{M}$ palmitate in the presence and absence of $25 \mu \mathrm{M}$ of the NFkB inhibitor BAY 11-7082 (Cayman Chemical, UK). All solutions were filter sterilised prior to use. For all treatments, medium was removed after $6 \mathrm{~h}$.

\section{Real-time PCR}

After the challenge, the medium was removed and cells were lysed using RLT lysis buffer (RNeasy Mini Kit Qiagen, Venlo, The Netherlands). Cell lysates were then collected and RNA extracted using an RNeasy Mini Kit (Qiagen) following the manufacturer's instructions. RNA integrity was assessed by an Agilent 2100 Bioanalyzer (Agilent Technologies, Amsterdam, The Netherlands). One microgram of total RNA was reverse transcribed to generate cDNA using Superscript II reverse transcriptase (Life Technologies, CA, USA). Real-time PCR was carried out using Taqman Fast Universal PCR master mix (Applied Biosystems, USA) according to manufacturer's instructions using the following Taqman assays: B2M (Mm00437762_m1), serpinA3N (Mm00776439_m1), IL-6 (Mm00446190_m1) and TNFa (Mm00443258_m1). Each reaction used $1 \mu \mathrm{L}$ of cDNA template.

\section{Western blotting}

N42 neurons were grown as described earlier. The cell culture medium was collected and protein concentrated using an Amicon Ultra-0.5 Centrifugal Filter (10 K device, Millipore, UK). For lysate preparation, cells were scraped into $1 \mathrm{ml}$ of PBS and pelleted by centrifugation; $1 \mathrm{ml}$ of M-PER mammalian protein extraction reagent (Thermo scientific) was added to the cell pellet before sonication using a Sanyo Soniprep 1500 to ensure complete cell lysis. Protein concentrations were determined using the Pierce $660 \mathrm{~nm}$ protein assay reagent (Thermo Scientific). Samples were then diluted 3:1 with $4 \times$ Laemmli sample buffer (Bio-Rad, UK) with 2-mercaptoethanol (9:1 ratio) and boiled for $10 \mathrm{~min}$, and $2 \mu \mathrm{g}$ of protein was loaded on the gels. For media in which no cells were cultured, used as a control, an amount equivalent to $5 \mu \mathrm{L}$ of concentrated media was loaded and as a positive control $12.5 \mathrm{ng}$ of recombinant mouse serpin $\alpha_{1} A C$ protein (R\&D Systems). Proteins were separated on 10\% mini-PROTEANTGX Precast Gels (Bio-Rad) and transferred to a PVDF Membrane (Bio-Rad) before immuno-detection using goat anti-mouse serpinA3N (R\&D Systems) and peroxidase-linked secondary antibody (Donkey polyclonal antibody to goat IgG (HRP), abcam, UK). Chemiluminescent signal on the blots was detected using a Fujifilm LAS-3000 Imager after incubation with Clarity Western ECL substrate kit (Bio-Rad) using the manufacturer's recommended protocol. Additional gels were run in parallel and stained with Colloidal Coomassie Blue (Safe Stain) (Severn Biotech Ltd) in order to visualise total protein present in cell media and lysates.

\section{Statistical analysis}

Data are presented as mean \pm SEM and were analysed using GenStat (GenStat, Eighth Edition (2005), VSN International Ltd., Oxford). In the case of experiments testing the influence of a single factor, a one-way ANOVA was performed. Where two or three factors were compared in a single experiment, a two- or three-way ANOVA followed by post hoc Student's $t$ tests based on the LSD were performed. In this case, the ANOVA results are expressed in the figure legend and the results of the Student $t$ test are represented on the graph. $P<0.05$ was considered statistically significant.

\footnotetext{
Abbreviations

AgRP: Agouti-related peptide; ANOVA: Analysis of variance; ARC: Arcuate nuclei; BSA: Bovine serum albumin; CART: Cocaine- and amphetamine-regulated transcript; $d b / d b$ : Diabetic obese mice with a spontaneous non-functional mutation in the leptin receptor; DMEM: Dulbecco's modified Eagle's medium; DMH: Dorsomedial nuclei of the hypothalamus; GFAP: Glial fibrillary acidic protein; HFD: High-fat diet; lba1: lonised calcium binding adaptor molecule 1; IKKß: Inhibitor of nuclear factor kappa-B kinase subunit $\beta$; IL-1: Interleukin-1; IL$1 R 1^{-1-}$ : Interleukin-1 receptor knockout mice; IL-6: Interleukin-6; IOD: Integrated optical density; IP: Intraperitoneal; JNK: c-Jun amino-terminal kinase; kCal: Kilocalories; LFD: Low-fat diet; LH: Lateral hypothalamus; LSD: Least significant difference; N42: mHypoE-N42 hypothalamic neuronal cell line; NFKB: Nuclear factor kappa-light-chain-enhancer of activated B cells;
} 
NPY: Neuropeptide Y; NuGO: Nutrigenomics Organization; ob/ob: Obese mice with a spontaneous mutation in the gene which produces leptin: PBS: Phosphate-buffered saline; POMC: Proopiomelanocortin; SEM: Standard error of the mean; SSC: Standard saline citrate; TLR4: Toll-like receptor 4; TNFa: Tumor necrosis factor alpha; UCD: University College Dublin; VMH: Ventromedial nuclei of the hypothalamus; $a_{1}$ AC: Alpha 1antichymotrypsin

\section{Funding}

$L M W, C G, A C M, E B, A M, B d R, M V B, M M$ and C-DM were supported by a project grant from NuGO; LMW, AM and FHM were supported by a project support grant from the British Society for Neuroendocrinology; DS was supported by a SULSA studentship; FHM was supported by a EASTBIO DTP BBSRC studentship; LMW, CG, ACM, EB, BdR, C-DM, FMC, PN, JED and NH were funded by the Scottish Government's Rural and Environment Science and Analytical Services Division (RESAS).

AT and KC were funded by the German Ministry of Research and Education (Ref. No: 0315087)

HMR was supported by the Irish Department of Agriculture, Food and Marine ImmunoMet Programme (14/F/828). FCM and HMR were supported by Science Foundation Ireland Principal Investigator Programme (11/PI/1119). RN and CD were supported by grants from Ministerio de Economia y Competitividad (CD: BFU2011-29102; RN: BFU2012-35255), Xunta de Galicia (RN: EM 2012/039 and 2012-CP069). Centro de Investigación Biomédica en Red (CIBER) de Fisiopatología de la Obesidad y Nutrición (CIBERobn). CIBERobn is an initiative of the Instituto de Salud Carlos III (ISCIII) of Spain which is supported by FEDER funds. The research leading to these results has also received funding from the European Community's Seventh Framework Programme under the following grants: no 245009: NeuroFAST to CD and ERC StG-2011-OBESITY53-281408 to RN.

\section{Availability of data and materials}

The transcriptomic data discussed in this publication have been deposited in NCBI's Gene Expression Omnibus [58] and are accessible through GEO Series accession number GSE113943 (https://www.ncbi.nlm.nih.gov/geo/query/ acc.cgi?acc=GSE113943) (https://www.ncbi.nlm.nih.gov/geo/query/acc.cgi).

\section{Authors' contributions}

DS, CG, ACM, E-MB, CK, FHM, BP, MVB, FCM, DK, PN and JB carried out the experimental work. DS, BdR FMC, C-DM, JD, HMR, MM, RN, CD, AT and LMW were responsible for the experimental design and data analysis and wrote the manuscript. All authors read and approved the final manuscript.

\section{Competing interests}

The authors declare that they have no competing interests.

\section{Publisher's Note}

Springer Nature remains neutral with regard to jurisdictional claims in published maps and institutional affiliations.

\section{Author details \\ ${ }^{1}$ Rowett Institute, University of Aberdeen, Aberdeen AB25 2ZD, UK. ${ }^{2}$ Department of Animal Physiology, Faculty of Biology, Philipps University Marburg, Karl-von-Frisch Str. 8, 35043 Marburg, Germany. ${ }^{3}$ Centre for Neuroendocrinology and Brain Health Research Centre, Department of Physiology, School of Medical Sciences, University of Otago, Dunedin 9054, New Zealand. ${ }^{4}$ Department of Physiology, University of Santiago de Compostela, 15705 Santiago de Compostela, Spain. ${ }^{5}$ CIBER Fisiopatología de la Obesidad y Nutrición (CIBERobn), Madrid, Spain. ${ }^{6}$ Nutrition, Metabolism and Genomics Group, Division of Human Nutrition, Wageningen University, Wageningen, The Netherlands. ${ }^{7}$ Nutrigenomics Research Group, UCD Conway Institute, University College Dublin, Dublin, Ireland. ${ }^{8}$ Biomathematics \& Statistics Scotland (BioSS), Rowett Institute, University of Aberdeen, Aberdeen AB25 2ZD, UK. ${ }^{9}$ Nutrigenomics and Systems Nutrition Group, Norwich Medical School, University of East Anglia, Norwich NR4 7UQ, UK.}

Received: 24 May 2018 Accepted: 6 November 2018

\section{Published online: 29 November 2018}

\section{References}

1. World Health Organisation. Obesity and overweight. Fact sheet No311. 2014.
2. Brown WW, Fujioka K, Wilson PW, Woodworth KA. Obesity: why be concerned? Am J Med. 2009;122:S4-11.

3. Luchsinger JA, Gustafson DR. Adiposity, type 2 diabetes, and Alzheimer's disease. J Alzheimers Dis. 2009;16:693-704.

4. Mann T, Tomiyama AJ, Westling E, Lew AM, Samuels B, Chatman J. Medicare's search for effective obesity treatments: diets are not the answer. Am Psychol. 2007;62:220-33.

5. Madsbad S, Dirksen C, Holst JJ. Mechanisms of changes in glucose metabolism and bodyweight after bariatric surgery. Lancet Diabetes Endocrinol. 2014;2:152-64.

6. Maclean PS, Bergouignan A, Cornier MA, Jackman MR. Biology's response to dieting: the impetus for weight regain. Am J Phys. 2011;301:R581-600.

7. Jeffery RW, Harnack LJ. Evidence implicating eating as a primary driver for the obesity epidemic. Diabetes. 2007;56:2673-6.

8. Berkseth KE, Guyenet SJ, Melhorn SJ, Lee D, Thaler JP, Schur EA, et al. Hypothalamic gliosis associated with high fat diet feeding is reversible in mice: a combined immunohistochemical and magnetic resonance imaging study. Endocrinology. 2014;141:2858-67.

9. Gao Y, Ottaway N, Schriever SC, Legutko B, Garcia-Caceres C, de IF, et al. Hormones and diet, but not body weight, control hypothalamic microglial activity. Glia. 2014;62:17-25.

10. Thaler JP, Schwartz MW. Minireview: inflammation and obesity pathogenesis: the hypothalamus heats up. Endocrinology. 2010;151:4109-15.

11. Zigman JM, Elmquist JK. Minireview: from anorexia to obesity--the yin and yang of body weight control. Endocrinology. 2003;144:3749-56.

12. Halaas $J L$, Boozer $C$, Blair-West J, Fidahusein N, Denton DA, Friedman JM. Physiological response to long-term peripheral and central leptin infusion in lean and obese mice. Proc Natl Acad Sci. 1997;94:8878-83.

13. Scarpace PJ, Zhang Y. Leptin resistance: a prediposing factor for dietinduced obesity. Am J Phys. 2009;296:R493-500.

14. Van Dijk G, De Vries K, Nyakas C, Buwalda B, Adage T, Kuipers F, et al. Reduced anorexigenic efficacy of leptin, but not of the melanocortin receptor agonist melanotan-II, predicts diet-induced obesity in rats. Endocrinology. 2005;146:5247-56.

15. Koch C, Augustine RA, Steger J, Ganjam GK, Benzler J, Pracht C, et al. Leptin rapidly improves glucose homeostasis in obese mice by increasing hypothalamic insulin sensitivity. J Neurosci. 2010;30:16180-7.

16. Tups A, Benzler J, Sergi D, Ladyman SR, Williams LM. Central regulation of glucose homeostasis. Compr Physiol. 2017;7:741-64.

17. Thaler JP, Yi CX, Schur EA, Guyenet SJ, Hwang BH, Dietrich MO, et al. Obesity is associated with hypothalamic injury in rodents and humans. J Clin Invest. 2012;122:153-62.

18. Milanski M, Degasperi G, Coope A, Morari J, Denis R, Cintra DE, et al. Saturated fatty acids produce an inflammatory response predominantly through the activation of TLR4 signaling in hypothalamus: implications for the pathogenesis of obesity. J Neurosci. 2009;29:359-70.

19. Kleinridders A, Schenten D, Konner AC, Belgardt BF, Mauer J, Okamura T, et al. MyD88 signaling in the CNS is required for development of fatty acid-induced leptin resistance and diet-induced obesity. Cell Metab. 2009;10:249-59.

20. Zhang $X$, Zhang G, Zhang H, Karin M, Bai H, Cai D. Hypothalamic IKKbeta/ NF-kappaB and ER stress link overnutrition to energy imbalance and obesity. Cell. 2008;135:61-73.

21. Cai D, Liu T. Inflammatory cause of metabolic syndrome via brain stress and NF-kappaB. Aging. 2012;4:98-115.

22. Koch CE, Lowe C, Pretz D, Steger J, Williams LM, Tups A. High-fat diet induces leptin resistance in leptin-deficient mice. J Neuroendocrinol. 2014; 26:58-67.

23. Hirosumi J, Tuncman G, Chang L, Gorgun CZ, Uysal KT, Maeda K, et al. A central role for JNK in obesity and insulin resistance. Nature. 2002;420:333-6.

24. Tuncman G, Hirosumi J, Solinas G, Chang L, Karin M, Hotamisligil GS. Functional in vivo interactions between JNK1 and JNK2 isoforms in obesity and insulin resistance. Proc Natl Acad Sci. 2006;103:10741-6.

25. Vijay-Kumar M, Aitken JD, Carvalho FA, Cullender TC, Mwangi S, Srinivasan S, et al. Metabolic syndrome and altered gut microbiota in mice lacking Tolllike receptor 5. Science. 2010;328:228-31.

26. Benzler J, Ganjam GK, Legler K, Stohr S, Kruger M, Steger J, et al. Acute inhibition of central c-Jun $\mathrm{N}$-terminal kinase restores hypothalamic insulin signalling and alleviates glucose intolerance in diabetic mice. J Neuroendocrinol. 2013;25:446-54.

27. Baker C, Belbin O, Kalsheker N, Morgan K. SERPINA3 (aka alpha-1antichymotrypsin). Front Biosci. 2007;12:2821-35. 
28. Zamanian JL, Xu L, Foo LC, Nouri N, Zhou L, Giffard RG, et al. Genomic analysis of reactive astrogliosis. J Neurosci. 2012;32:6391-410.

29. Sardi F, Fassina L, Venturini L, Inguscio M, Guerriero F, Rolfo E, et al. Alzheimer's disease, autoimmunity and inflammation. The good, the bad and the ugly. Autoimmun Rev. 2011;11:149-53.

30. Furby A, Leys D, Delacourte A, Buee L, Soetaert G, Petit H. Are alpha-1antichymotrypsin and inter-alpha-trypsin inhibitor peripheral markers of Alzheimer's disease? J Neurol Neurosurg Psychiatry. 1991;54:469.

31. Cichy J, Potempa J, Chawla RK, Travis J. Stimulatory effect of inflammatory cytokines on alpha 1-antichymotrypsin expression in human lung-derived epithelial cells. J Clin Invest. 1995;95:2729-33.

32. Cichy J, Potempa J, Chawla RK, Travis J. Regulation of alpha 1-antichymotrypsin synthesis in cells of epithelial origin. FEBS Lett. 1995;359:262-6.

33. Mrak RE, Griffin WS. Interleukin-1 and the immunogenetics of Alzheimer disease. J Neuropathol Exp Neurol. 2000;59:471-6.

34. Machein U, Lieb K, Hull M, Fiebich BL. IL-1 beta and TNF alpha, but not IL-6, induce alpha 1-antichymotrypsin expression in the human astrocytoma cell line U373 MG. Neuroreport. 1995;6:2283-6.

35. Cai D. Neuroinflammation in overnutrition-induced diseases. Vitam Horm. 2013;91:195-218

36. Williams LM. Hypothalamic dysfunction in obesity. Proc Nutr Soc. 2012;71:521-33.

37. Dickson I, Alper CA. Changes in serum proteinase inhibitor levels following bone surgery. Clin Chim Acta. 1974;54:381-5.

38. Zhang S, Janciauskiene S. Multi-functional capability of proteins: alpha1antichymotrypsin and the correlation with Alzheimer's disease. J Alzheimers Dis. 2002;4:115-22

39. Licastro F, Mallory M, Hansen LA, Masliah E. Increased levels of alpha-1antichymotrypsin in brains of patients with Alzheimer's disease correlate with activated astrocytes and are affected by APOE 4 genotype. J Neuroimmunol. 1998;88:105-10.

40. Abraham CR, Selkoe DJ, Potter H. Immunochemical identification of the serine protease inhibitor alpha 1-antichymotrypsin in the brain amyloid deposits of Alzheimer's disease. Cell. 1988;52:487-501.

41. Kilpatrick L, Johnson JL, Nickbarg EB, Wang ZM, Clifford TF, Banach M, et al. Inhibition of human neutrophil superoxide generation by alpha 1antichymotrypsin. J Immunol. 1991;146:2388-93.

42. Takada S, Tsuda M, Yamamura M, Katsunuma T. Effect of alpha-1antichymotrypsin on activity of DNA primase isolated from human stomach adenocarcinoma cells. Biochem Int. 1988;16:949-54.

43. Tsuda M, Masuyama M, Katsunuma T. Inhibition of human DNA polymerase alpha by alpha 1-antichymotrypsin. Cancer Res. 1986;46:6139-42.

44. Titolo D, Cai F, Belsham DD. Coordinate regulation of neuropeptide $Y$ and agouti-related peptide gene expression by estrogen depends on the ratio of estrogen receptor (ER) a to ERß in clonal hypothalamic neurons. Mol Endocrinol. 2006;20:2080-92.

45. Buckman LB, Thompson MM, Moreno HN, Ellacott KL. Regional astrogliosis in the mouse hypothalamus in response to obesity. J Comp Neurol. 2013; 521:1322-33.

46. Bode JG, Albrecht U, Haussinger D, Heinrich PC, Schaper F. Hepatic acute phase proteins-regulation by IL-6- and IL-1-type cytokines involving STAT3 and its crosstalk with NF-kappaB-dependent signaling. Eur J Cell Biol. 2012;91:496-505.

47. Luheshi GN, Gardner JD, Rushforth DA, Loudon AS, Rothwell NJ. Leptin actions on food intake and body temperature are mediated by IL-1. Proc Natl Acad Sci. 1999;96:7047-52.

48. Lyons $\mathrm{CL}$, Kennedy EB, Roche HM. Metabolic inflammation-differential modulation by dietary constituents. Nutrients. 2016;8:247.

49. Rivest S. How circulating cytokines trigger the neural circuits that control the hypothalamic-pituitary-adrenal axis. Psychoneuroendocrinology. 2001;26:761-88.

50. Kim JG, Suyama S, Koch M, Jin S, Argente-Arizon P, Argente J, Liu ZW, Zimmer MR, Jeong JK, Szigeti-Buck K, Gao Y, Garcia-Caceres C, Yi CX, Salmaso N, Vaccarino FM, Chowen J, Diano S, Dietrich MO, Tschöp MH, Horvath TL. Leptin signaling in astrocytes regulates hypothalamic neuronal circuits and feeding. Nat Neurosci. 2014;17:908-10.

51. Hardie LJ, Rayner DV, Holmes S, Trayhurn P. Circulating leptin levels are modulated by fasting, cold exposure and insulin administration in lean but not Zucker (fa/fa) rats as measured by ELISA. Biochem Biophys Res Commun. 1996; 223:660-5.

52. Teusink B, Voshol PJ, Dahlmans VE, Rensen PC, Pijl H, Romijn JA, Havekes $L M$. Contribution of fatty acids released from lipolysis of plasma triglycerides to total plasma fatty acid flux and tissue-specific fatty acid uptake. Diabetes. 2003:52:614-20
53. Flurkey K, Currer JM, Harrison D. Mouse models in aging research. In: The mouse in biomedical research. 2nd ed. Amsterdam: Elsevier; 2007. p. 637-72.

54. Zhang G, Li J, Purkayastha S, Tang Y, Zhang H, Yin Y, Li B, Liu G, Cai D. Hypothalamic programming of systemic ageing involving IKK-B, NF-KB and GnRH. Nature. 2013;497:211-6.

55. Baccini M, Bachmaier EM, Biggeri A, Boekschoten MV, Bouwman FG, Brennan $L$, et al. The NuGO proof of principle study package: a collaborative research effort of the European Nutrigenomics Organisation. Genes Nutr. 2008;3:147-51.

56. Mitchell SE, Robinson JJ, King ME, McKelvey WAC, Williams LM. Interleukin-8 in the cervix of non-pregnant ewes pregnancy. Reproduction. 2002;124:409-16.

57. Paxinos G, Tork I, Tecott LH, Valentino KL. Atlas of the developing rat brain. San Diego: Academic; 1991.

58. Edgar R, Domrachev M, Lash AE. Gene Expression Omnibus: NCBI gene expression and hybridization array data repository. Nucleic Acids Res. 2002; 30:207-10.
Ready to submit your research? Choose BMC and benefit from:

- fast, convenient online submission

- thorough peer review by experienced researchers in your field

- rapid publication on acceptance

- support for research data, including large and complex data types

- gold Open Access which fosters wider collaboration and increased citations

- maximum visibility for your research: over 100M website views per year

At $\mathrm{BMC}$, research is always in progress.

Learn more biomedcentral.com/submissions 